\title{
Single photon emission computed tomography (SPECT) of anxiety disorders before and after treatment with citalopram Paul D Carey*1, James Warwick ${ }^{2}$, Dana JH Niehaus ${ }^{1}$, Geoffrey van der Linden ${ }^{1}$, Barend B van Heerden ${ }^{2}$, Brian H Harvey ${ }^{3}$, Soraya Seedat ${ }^{1}$ and Dan J Stein ${ }^{1}$
}

Address: ${ }^{1}$ MRC Unit on Anxiety Disorders, Department of Psychiatry, University of Stellenbosch, Tygerberg, 7505, Cape Town, South Africa, ${ }^{2}$ Department of Nuclear Medicine, University of Stellenbosch, Tygerberg, 7505, Cape Town, South Africa and ${ }^{3}$ School of Pharmacy (Pharmacology), North-West University, Potchefstroom, South Africa

Email: Paul D Carey* - pcarey@sun.ac.za; James Warwick - jw@sun.ac.za; Dana JH Niehaus - djhn@sun.ac.za; Geoffrey van der Linden - geoff@vanderlinden.fsnet.co.uk; Barend B van Heerden - bbvh@sun.ac.za; Brian H Harvey - FKLBHH@puk.ac.za;

Soraya Seedat - sseedat@sun.ac.za; Dan J Stein - djs2@sun.ac.za

* Corresponding author

Published: 14 October 2004

BMC Psychiatry 2004, 4:30 doi:10.1 186/147I-244X-4-30
Received: 04 May 2004

Accepted: 14 October 2004

This article is available from: http://www.biomedcentral.com/I47I-244X/4/30

(c) 2004 Carey et al; licensee BioMed Central Ltd.

This is an open-access article distributed under the terms of the Creative Commons Attribution License (http://creativecommons.org/licenses/by/2.0), which permits unrestricted use, distribution, and reproduction in any medium, provided the original work is properly cited.

\begin{abstract}
Background: Several studies have now examined the effects of selective serotonin reuptake inhibitor (SSRI) treatment on brain function in a variety of anxiety disorders including obsessive-compulsive disorder (OCD), posttraumatic stress disorder (PTSD), and social anxiety disorder (social phobia) (SAD). Regional changes in cerebral perfusion following SSRI treatment have been shown for all three disorders. The orbitofrontal cortex (OFC) (OCD), caudate (OCD), medial pre-frontal/cingulate (OCD, SAD, PTSD), temporal (OCD, SAD, PTSD) and, thalamic regions (OCD, SAD) are some of those implicated. Some data also suggests that higher perfusion pre-treatment in the anterior cingulate (PTSD), OFC, caudate (OCD) and antero-lateral temporal region (SAD) predicts subsequent treatment response. This paper further examines the notion of overlap in the neurocircuitry of treatment and indeed treatment response across anxiety disorders with SSRI treatment.
\end{abstract}

Methods: Single photon emission computed tomography (SPECT) using Tc-99 m HMPAO to assess brain perfusion was performed on subjects with OCD, PTSD, and SAD before and after 8 weeks (SAD) and 12 weeks (OCD and PTSD) treatment with the SSRI citalopram. Statistical parametric mapping (SPM) was used to compare scans (pre- vs post-medication, and responders vs non-responders) in the combined group of subjects.

Results: Citalopram treatment resulted in significant deactivation $(p=0.00 \mathrm{I})$ for the entire group in the superior $(t=4.78)$ and anterior $(t=4.04)$ cingulate, right thalamus $(t=4.66)$ and left hippocampus $(t=3.96)$. Deactivation $(p=0.00 \mathrm{I})$ within the left precentral $(t=4.26)$, right mid-frontal $(t=4.03)$, right inferior frontal $(t=3.99)$, left prefrontal (3.8I) and right precuneus $(t=3.85)$ was more marked in treatment responders. No pattern of baseline activation distinguished responders from non-responders to subsequent pharmacotherapy.

Conclusions: Although each of the anxiety disorders may be mediated by different neurocircuits, there is some overlap in the functional neuro-anatomy of their response to SSRI treatment. The current data are consistent with previous work demonstrating the importance of limbic circuits in this spectrum of disorders. These play a crucial role in cognitive-affective processing, are innervated by serotonergic neurons, and changes in their activity during serotonergic pharmacotherapy seem crucial. 


\section{Background}

Significant advances in our understanding of the mediating psychobiology and the development of effective treatments for anxiety disorders have been made in recent years. Modern brain imaging techniques have proved useful in exposing specific albeit overlapping neurocircuitry that underlies individual anxiety disorders $[1,2]$. However, relatively little work has focused on the extent to which the anxiety disorders overlap with respect to changes in brain perfusion that accompany response to first-line treatment that is after all pharmacologically similar for different disorders.

The selective serotonin reuptake inhibitors (SSRIs) are currently recommended as first line medications for most anxiety disorders, including obsessive-compulsive disorder (OCD) [3], posttraumatic stress disorder [4] and social anxiety disorder [5]. A number of imaging studies have now examined the effects of SSRI's on brain perfusion in individual anxiety disorders. In OCD, attenuation of pre-treatment regional activation has been shown to correlate with treatment response in the anterolateral orbitofrontal cortex (OFC), caudate nucleus, thalamus, and temporal regions [6-11]. Results for studies assessing pre-treatment cerebral perfusion as a predictor of response, have, however, yielded mixed results. In some, an inverse relationship appears to exist with pre-treatment regional activation of the OFC [12], anterior cingulate, caudate [6] and subsequent responses to treatment. Conversely findings of higher prefrontal, cingulate and basal ganglia activation correlating with subsequent treatment response have also been reported $[13,14]$. In OCD comorbid with depression, substrates of response to the SSRI, paroxetine, appear to differ based on pretreatment [15] activation patterns as well as changes that accompany treatment response when an SSRI is given in identical doses for either of the two conditions separately [16].

In social anxiety disorder SSRI treatment response accompanies attenuation of frontal, anterior and lateral temporal cortex, cingulate, and thalamic activity $[17,18]$. Higher anterior and lateral temporal cortical perfusion at baseline correlated with subsequent treatment response in the former study. The latter study also demonstrated some overlap of regions demonstrating attenuation of activity for both cognitive and pharmacotherapy interventions.

In PTSD, a single study by our group demonstrated medial temporal lobe deactivation with treatment irrespective of clinical response and medial prefrontal cortex activation correlated with treatment response. In addition, no baseline differences distinguished responders and nonresponders to subsequent SSRI treatment [19].
In this present study, we hypothesised firstly, that response to SSRI treatment in this combined group of subjects with anxiety disorders (OCD, PTSD, SAD) would effect shared changes in rCBF affecting primarily limbic and related prefrontal regions and thus suggest some overlap between disorders in the mechanism of their response to effective treatment with SSRI's. Secondly, pre-treatment differences in regional perfusion would likely differentiate responders to subsequent treatment with citalopram across the anxiety disorders.

\section{Methods \\ Subjects}

Adult subjects with a primary diagnosis of OCD $(\mathrm{n}=11)$, PTSD $(n=11)$ or SAD $(n=15)$ were recruited from the Anxiety Disorders Clinic of our tertiary hospital. All subjects were interviewed with the Structured Clinical Interview for the Diagnosis of Axis-I Disorders [20] to ascertain diagnosis according to DSM-IV criteria. Results for the PTSD group have been reported previously [19].

Comorbid major depression was an exclusion criterion in the OCD and SAD, but not in the PTSD subjects. Nevertheless, in all cases comorbid disorders were considered secondary in terms of temporal course, symptom severity, and associated distress. Patients previously treated with SSRI's had been free of medication for a minimum of four weeks for fluoxetine and two weeks for other SSRI's. In total $30(81 \%)$ of the group were SSRI naïve. Subjects with other central nervous system disorders including previous head injury or epilepsy were excluded. The Institutional Review Board of our University approved the protocol and all patients gave informed written consent after a full explanation of the possible risks and benefits.

\section{Pharmacotherapy and measures}

All patients underwent treatment with citalopram, the most selective of the currently available selective serotonin reuptake inhibitors (SSRIs). The duration of the trial of treatment was 12 weeks for OCD and PTSD, and 8 weeks for SAD.

Dosage was initiated at $20 \mathrm{mg}$ daily for the first two weeks and then maintained at $40 \mathrm{mg}$ daily for the remainder of the study. Measures of symptom improvement were made bi-weekly by clinicians using the Clinical Global Impressions (CGI) scale [21]. Subjects with a CGI change score of 2 or less post-treatment were defined as responders, while those with scores greater than 2 were defined as non-responders.

Anxiety symptoms were also rated using disorder specific scales including the Liebowitz Social Anxiety Scale(LSAS) [22], the Yale Brown Obsessive-Compulsive Scale (YBOCS) [23] and the Clinician Administered Scale for 
PTSD [24]. Depressive symptoms were rated using the Montgomery-Asberg Depression Rating Scale (MADRS) [25].

\section{SPECT imaging}

Single photon emission computed tomography (SPECT) was conducted before and after pharmacotherapy. Subjects lay supine in a quiet dimly lit room for 30 minutes prior to injection of the radiopharmaceutical. Apart from administration of the injection by a physician, they remained alone in the room during this period. Subjects were asked to remain at rest during the 30 minute period and for 10 minutes after injection of the radiopharmaceutical.

An injection of $555 \mathrm{MBq}(15 \mathrm{mCi})$ of technetium-99 m hexamethylpropylene amine oxime (Tc-99 m HMPAO) was given into an arm vein through a previously placed intravenous cannula. After completion of the rest period, SPECT imaging of the brain was performed, with the subject's head supported by a headrest, using a dual detector gamma camera (Elscint, Helix, GE Medical Systems, USA) equipped with fan beam collimators.

Data were acquired in the step-and-shoot mode, using a 360 degree circular orbit, with the detectors of the gamma camera as close as possible to the subject's head. The height of the imaging table and radius of rotation were noted for each subject and the same measurements were used for the follow-up study. Data were acquired using a $128 \times 128$ image matrix in 3 degree steps of 15 seconds per step.

Data were reconstructed by filtered backprojection, using a Metz filter (power $=5$, FWHM $=14 \mathrm{~mm}$ ) and a zoom factor of 2.29. The Chang (1978) method was used for attenuation correction. Scatter correction was not performed. The final reconstructed pixel size was $3.87 \mathrm{~mm}$ by $3.87 \mathrm{~mm}$. Image files were converted from interfile to analyze format using conversion software (Medcon, Erik Nolf, UZ Ghent).

Stastical analyses were conducted on a voxel-by-voxel basis using the Statistical Parametric Mapping (SPM99, Wellcome Department of Cognitive Neurology, UK) [26]. The realign function was used to co-register baseline and posttreatment SPECT images for each subject and to generate a mean image for each subject. Realigned images were then normalised to the Montreal Neurological Institute (MNI) standard anatomical space to a value of 50 using proportional scaling. For this the transform function from the mean image for each subject to the normalised image with $4 \mathrm{~mm}^{3}$ voxels using 12 affine transformations and $7 \times 8 \times 7$ non-linear basis functions was used. Standardised images were then smoothed using a Gaussian kernel with a FWHM of $12 \mathrm{~mm}^{3}$.

A multi-group study design was performed using 2 groups (responders and non-responders) with 2 conditions each (pre- and post-treatment). Contrasts were applied to look for areas of significant change post-treatment compared to pre-treatment. Contrasts were also used to search for areas of relative change in treatment responders compared to non-responders. A second design was employed to compare the baseline scans of responders to SSRI pharmacotherapy with those of non-responders. Contrasts were used to search for regions of significant differences on the baseline scans of responders compared to non-responders.

In view of a priori knowledge suggesting involvement of the cingulate, hippocampus, inferior frontal cortex, and striatum in the anxiety disorders, an uncorrected p-value of $\mathrm{p}<0.001$ corresponding to a $\mathrm{t}$ value of 3.34 , was chosen for the analysis of these regions in order to minimize type I errors. Given the relative paucity of data in this area, we chose this uncorrected p-value, based on work using a similar methodology [19]. In order to minimize type I errors a significance level of $\mathrm{p}<0.05$ corrected for Gaussian Random Field Theory was used for the remainder of the brain. A spatial extent threshold of 5 voxels was also used at all times. Masking using a threshold proportional to 0.4 times the mean voxel value was used to minimize the analysis of voxels not located in grey matter. Furthermore, clusters were ignored if co-registration with a SPECT template demonstrated that they were located outside of grey matter.

\section{Results}

Twenty-two males and fifteen females with a mean age of 33.5 years (SD 9.8) completed the study. Clinical changes with pharmacotherapy for each disorder are provided in Table 1 . This shows that for each of the anxiety disorders being studied, citalopram was effective in significantly reducing clinical measures of severity as determined by a CGI change score of 2 or less (much or very much improved). As such, 20 of 37 patients (54\%) were responders to citalopram.

Comparison of pre- and post-treatment scans for the whole group showed decreased activity in 4 significant clusters in grey matter (Figure 1): These included the superior cingulate, right thalamus, anterior cingulate, and the left hippocampus (Table 2). Comparison of pre- and postmedication scans showed no significant areas of activation.

Comparison of responders with non-responders demonstrated that responders had a significantly greater decrease 
Table I: Clinical parameters for all the groups (mean \pm SD), (paired t-test).

\begin{tabular}{|c|c|c|c|c|}
\hline & & Baseline & Endpoint & $\mathbf{p}$ \\
\hline \multirow[t]{4}{*}{$O C D(n=11)$} & YBOCS & $26.6 \pm 4.7$ & $23.7 \pm 5.8$ & 0.001 \\
\hline & MADRS & $13.64 \pm 9.6$ & $9.9 \pm 6.4$ & 0.119 \\
\hline & CGl-severity & $4.7 \pm 0.647$ & $4.18 \pm 1.1$ & 0.025 \\
\hline & CGl-improvement & & $3.1 \pm 0.7$ & \\
\hline \multirow[t]{4}{*}{$\operatorname{SAD}(n=15)$} & LSAS & $79.2 \pm 30.2$ & $63.1 \pm 28.5$ & 0.003 \\
\hline & MADRS & $15 \pm 4.9$ & $9.1 \pm 5.9$ & 0.004 \\
\hline & CGI-severity & $4.6 \pm 0.8$ & $3.3 \pm 1.1$ & 0.001 \\
\hline & CGl-improvement & & $2.7 \pm 1.2$ & \\
\hline \multirow[t]{4}{*}{$\operatorname{PTSD}(\mathrm{n}=1 \mathrm{I})$} & CAPS & $78.1 \pm 16.9$ & $45.5 \pm 23.9$ & $<0.01$ \\
\hline & MADRS & $25 \pm 6.7$ & $15.9 \pm 8.0$ & $<0.01$ \\
\hline & CGI -severity & $4.5 \pm 0.5$ & $2.5 \pm 0.7$ & $<0.01$ \\
\hline & CGl-improvement & & $1.9 \pm 0.7$ & \\
\hline
\end{tabular}

YBOCS, Yale Brow Obsessive-compulsive scale; MADRS, Montgomery Asberg Depression Rating scale; CGI-s, Clinical global impressions severity; CGI-I, Clinical global impressions - improvement; LSAS, Liebowitz Social Anxiety Scale; CAPS, Clinician Administered PTSD scale.

of activity in 4 clusters (Figure 2). These clusters were localised to the left precentral, right middle frontal, right inferior frontal and, left prefrontal regions (Table 3). Comparison of baseline scans of responders and nonresponders did not reveal any significant differences.

\section{Discussion}

The main finding of this paper was that citalopram pharmacotherapy resulted in significant deactivation within anterior and superior cingulate cortex, the left hippocampus and the right thalamus in a combined group of patients with different anxiety disorders (OCD, PTSD, and SAD). Furthermore, deactivation was significantly more apparent in responders than in non-responders to SSRI treatment within precentral, right inferior, middle frontal and left prefrontal regions. Interestingly, no pre-treatment differences in regional perfusion between subsequent treatment responders vs non-responders were found.

Although there are important differences in the symptomatology of the anxiety disorders, these conditions do share certain aspects of their phenomenology, including heightened anxiety and avoidance behaviour. Furthermore, previous functional brain imaging work has demonstrated overlapping neurocircuitry across different anxiety disorders with activation of paralimbic circuitry and right inferior frontal cortex in a combined group comprising subjects with OCD, PTSD, and specific phobia [1]. Results in the present study now also point to an overlap in the functional neuroanatomy, primarily implicating paralimbic neurocircuitry, in treatment response to the same SSRI, citalopram, across anxiety disorders. In citalopram responders, effects across disorders were most pronounced in the mid, inferior and prefrontal cortex. In other regions, such as the striatum, data on treatment response and symptom provocation seems to indicate less overlap across anxiety disorders, which may suggest only partial and regionally specific overlap between disorders $[1,2]$.

Specific limbic regions are well-known to play a role in broadly mediating anxiety. Early observations of epileptogenic cingulate lesions support its role in regulating affect [27]. Furthermore, recent work has suggested a role for the anterior cingulate in integrating cognitive and motivational processes. These include evaluating environmental cues and monitoring performance [28] On the other hand, a central role for the hippocampus in contextual aspects of fear conditioning has been demonstrated $[29,30]$.

The findings here complement previous studies of OCD, PTSD, and SAD that have demonstrated a specific role for the cingulate and hippocampus in these conditions. Studies in OCD have shown increased anterior cingulate activity at baseline, or deactivation during pharmacotherapy with serotonergic agents [31]. In PTSD, anterior cingulate activity is also increased in some, although not all, studies of PTSD [32,33] Further, the anterior cingulate is deactivated during citalopram treatment of SAD patients [17]. Dysfunction of the hippocampus, as indicated by smaller hippocampal volume and declarative memory deficits, may play an important role in PTSD [34].

The medial prefrontal cortex comprises several related areas including anterior cingulate cortex. Lesions of this area are associated with suboptimal responses to stress, and the area has important inhibitory inputs to the amygdala which mediate extinction of fear conditioning [29]. The middle and inferior frontal cortex, on the other hand, is involved in encoding and retrieval of verbal memories. Our finding that the right inferior frontal cortex was more 

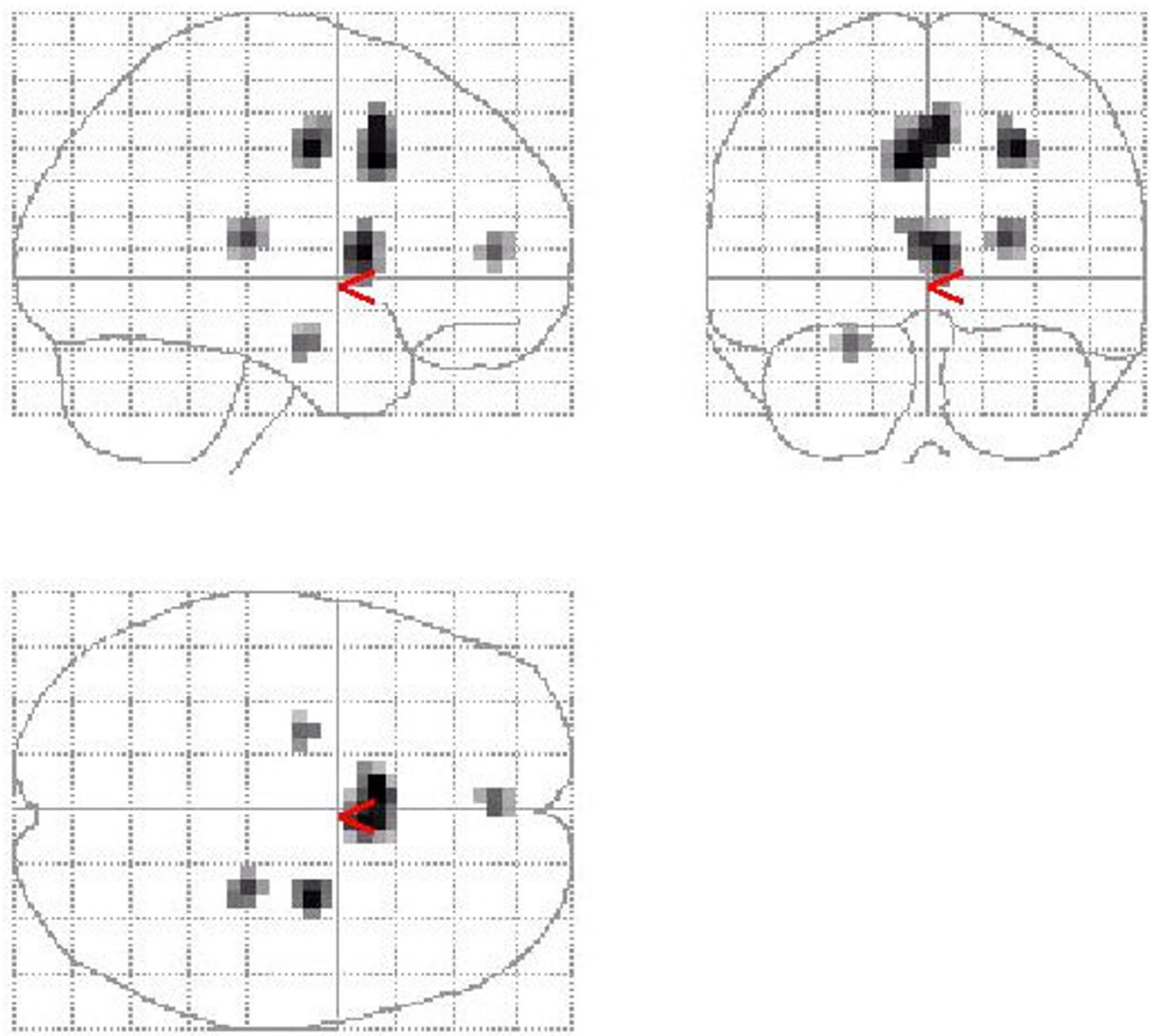

Figure I

Combined group deactivation following treatment with citalopram. Regions of deactivation for the combined group of OCD + SAD + PTSD following treatment with citalopram. Significant grey matter clusters are seen in the superior cingulate, anterior cingulate, left medial temporal region (hippocampus).

Table 2: Localisation of significant clusters of deactivation following treatment for the combined group of OCD, SAD, PTSD. $Z_{\text {max }}$ set to threshold of $t=3.34$ corresponding to $p<0.001$

\begin{tabular}{cccc}
\hline Cluster size (voxels) & $\mathrm{t}$ & MNI co-ordinates $(\mathbf{x}, \mathbf{y}, \mathbf{z})$ & Brain region \\
\hline 44 & 4.78 & $-4,12,36$ & Superior cingulate \\
19 & 4.66 & $24,-28,12$ & Right thalamus \\
10 & 4.04 & $0,48,8$ & Anterior cingualate \\
7 & 3.96 & $-24,-12,-20$ & Left hippocampus \\
\hline
\end{tabular}



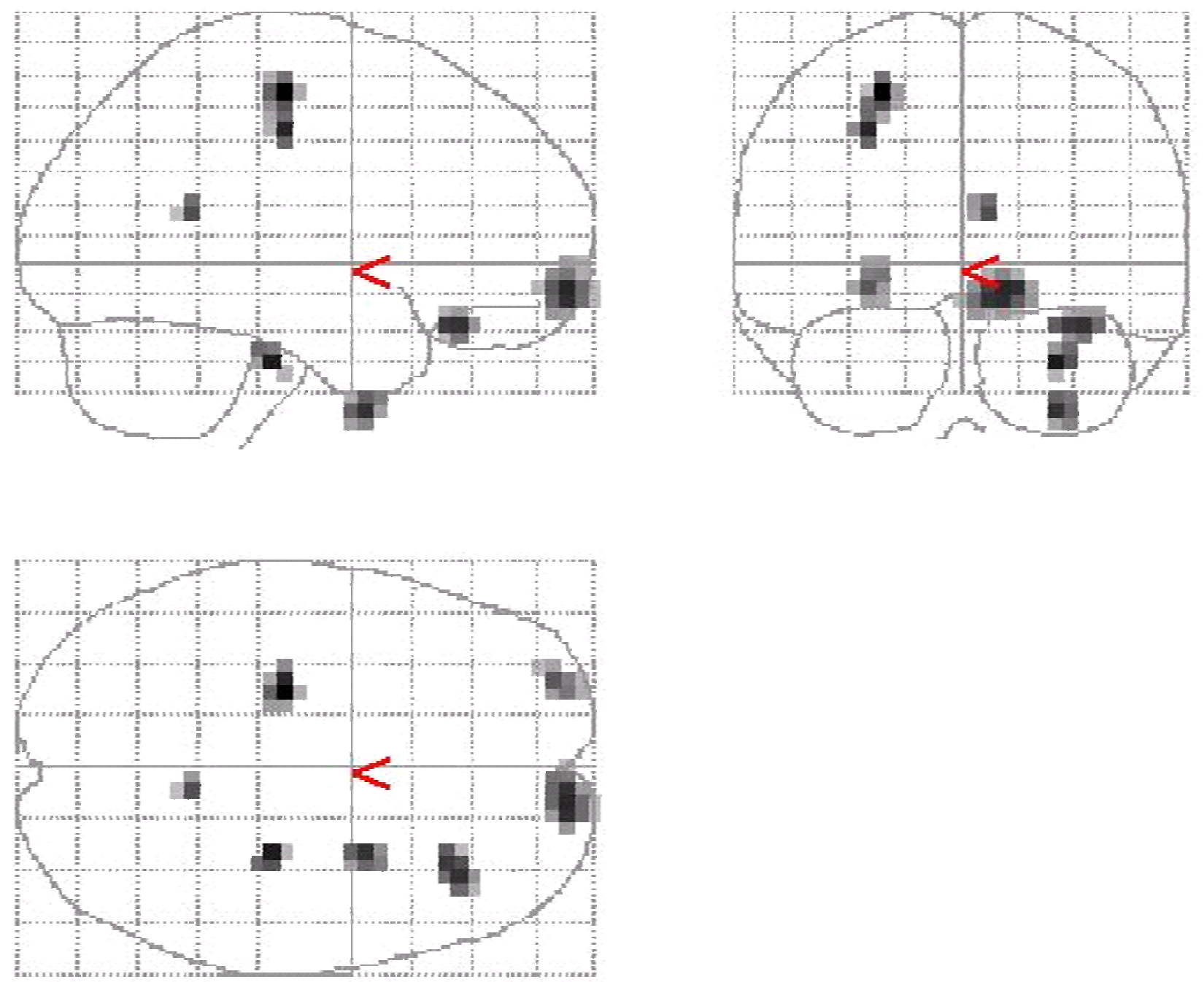

Figure 2

Regional deactivation (responders > non-responders). Grey matter clusters of greater deactivation in responders vs non-responders were detected in the left precentral, prefrontal and right mid - and inferior-frontal regions.

Table 3: Localisation of significant clusters of deactivation in responders vs non-responders to SSRI treatment for the combined group of OCD, SAD, PTSD. $Z_{\max }$ set to threshold of $t=3.34$ corresponding to $p<0.00 \mathrm{I}$

\begin{tabular}{cccc}
\hline Cluster size (voxels) & $\mathrm{t}$ & MNI co-ordinates $(\mathbf{x}, \mathbf{y}, \mathbf{z})$ & Brain region \\
\hline 21 & 4.26 & $-24,-20,56$ & Left precentral \\
33 & 4.03 & $12,64,-8$ & Right mid-frontal \\
17 & 3.99 & $36,32,-20$ & Right inferior frontal cortex \\
5 & 3.85 & $8,-48,16$ & Right precuneus \\
18 & 3.81 & $-28,60,-8$ & Left prefrontal \\
\hline
\end{tabular}


deactivated in responders is perhaps consistent with previous findings showing increased activity pre-treatment in this region across different anxiety disorders [2] and in some, but not all, studies of PTSD [35].

Serotonergic circuits innervate the medial prefrontal cortex and other limbic structures, and chronic administration of a serotonin reuptake inhibitor may lead to an increase in their neurotransmission. It is possible that the medial prefrontal cortex deactivation during serotonergic pharmacotherapy indicates that a compensatory increase of activity in this region is no longer needed after symptom improvement. Along these lines, a number of functional and electrophysiological imaging studies of depression have found that anterior cingulate hyperactivity predicts a positive response to pharmacotherapy, a finding that has also been interpreted as indicating the baseline presence of an adaptive compensatory response [36]. In addition changes in cognitive processing of frontal cortex may be secondary to symptom reduction caused by primary drug-induced changes within the limbic system. We have previously demonstrated similarly higher pre-treatment prefrontal perfusion in subsequent responders relative to non-responders using inositol in OCD [37]. Interestingly, inositol responsive disorders overlap with those responsive to SSRI's which may suggest that it is serotonergic components of these disorders that account for at least some of the overlap in perfusion patterns demonstrated here.

In contrast, however, increased activity in anterior cingulate or orbitofrontal region in OCD has also been shown to predict a poorer response to pharmacotherapy [9].

Perhaps increased activity in particular limbic circuits plays a different functional role in different psychiatric disorders. Only limited functional imaging studies of pharmacotherapy effects have involved provocation paradigms [38] and such differences in design may account for certain inconsistencies across studies. Alternatively, it is feasible that different effects in different disorders may also help explain inconsistencies. In the current dataset, however, we were unable to demonstrate any associations between baseline activity and pharmacotherapy response for the combined group.

This study is limited by the slightly different inclusion criteria (inclusion of secondary depression in PTSD group) and pharmacotherapy duration for different disorders. While the absence of untreated controls may to some extent limit the conclusions we can draw, comparing nonresponders to responders we believe serves as a reasonable evaluation of changes that result from treatment response. The lower spatial resolution of SPECT may be considered a limitation nevertheless this study usefully emphasizes the importance of limbic regions (amygdala, hippocampus) in mediating anxiety. Furthermore, deactivation within these regions as well as richly connected frontal regions following SSRI treatment, particularly in responders, is clearly demonstrated. Further research combining pharmacological interventions and functional methodologies, and using tracers tailored to specific neurotransmitter receptors, will undoubtedly lead to increased understanding of the pathogenesis of the anxiety disorders and the mechanisms of response to treatment in the future.

\section{Competing interests}

The authors declare that they have no competing interests.

\section{Authors' contributions}

The authors contributed to the work in the following ways: drafting of manuscript (PDC, JW, DJS), data analysis (JW, PDC), psychiatric evaluations (DJHN, GVDL, SS, DJS), SPECT imaging (JW, BBVH). All authors have read and approved the final manuscript.

\section{Acknowledgements}

This study was supported by the Medical Research Council of South Africa. Medication was provided by Lundbeck South Africa.

\section{References}

I. Lucey JV, Costa DC, Busatto G, Pilowsky LS, Marks IM, Ell PJ, Kerwin RW: Caudate regional cerebral blood flow in obsessive-compulsive disorder, panic disorder and healthy controls on single photon emission computerised tomography. Psychiatry Res 1997, 74:25-33.

2. Rauch SL, Savage CR, Alpert NM, Fischman AJ, Jenike MA: The functional neuroanatomy of anxiety: a study of three disorders using positron emission tomography and symptom provocation. Biol Psychiatry 1997, 42:446-452.

3. Kaplan A, Hollander E: A review of pharmacologic treatments for obsessive-compulsive disorder. Psychiatr Serv 2003, 54: $1111-1118$.

4. Stein DJ, Seedat S, van der Linden GJ, Zungu-Dirwayi N: Selective serotonin reuptake inhibitors in the treatment of post-traumatic stress disorder: a meta-analysis of randomized controlled trials. Int Clin Psychopharmacol 2000, 15 Suppl 2:S3 I-S39.

5. van der Linden G], Stein DJ, van Balkom AJ: The efficacy of the selective serotonin reuptake inhibitors for social anxiety disorder (social phobia): a meta-analysis of randomized controlled trials. Int Clin Psychopharmacol 2000, 15 Suppl 2:SI5-S23.

6. Hendler T, Goshen E, Tzila Zwas S., Sasson Y, Gal G, Zohar J: Brain reactivity to specific symptom provocation indicates prospective therapeutic outcome in OCD. Psychiatry Res 2003, 1 24:87-103.

7. Molina V, Montz R, Martin-Loeches M, Jimenez-Vicioso A, Carreras JL, Rubia FJ: Drug therapy and cerebral perfusion in obsessivecompulsive disorder. J Nucl Med 1995, 36:2234-2238.

8. Saxena S, Brody AL, Maidment KM, Dunkin IJ, Colgan M, Alborzian S, Phelps ME, Baxter L.R.,Jr.: Localized orbitofrontal and subcortical metabolic changes and predictors of response to paroxetine treatment in obsessive-compulsive disorder. Neuropsychopharmacology 1999, 21:683-693.

9. Brody AL, Saxena S, Schwartz JM, Stoessel PW, Maidment K, Phelps ME, Baxter L.R.,Jr.: FDG-PET predictors of response to behavioral therapy and pharmacotherapy in obsessive compulsive disorder. Psychiatry Res 1998, 84: I-6.

10. Baxter L.R.,Jr., Schwartz JM, Bergman KS, Szuba MP, Guze BH, Mazziotta JC, Alazraki A, Selin CE, Ferng HK, Munford P, .: Caudate glucose metabolic rate changes with both drug and behavior 
therapy for obsessive-compulsive disorder. Arch Gen Psychiatry 1992, 49:68I-689.

II. Benkelfat C, Nordahl TE, Semple WE, King AC, Murphy DL, Cohen RM: Local cerebral glucose metabolic rates in obsessive-compulsive disorder. Patients treated with clomipramine. Arch Gen Psychiatry 1990, 47:840-848.

12. Rauch SL, Shin LM, Dougherty DD, Alpert NM, Fischman AJ, Jenike $M A$ : Predictors of fluvoxamine response in contaminationrelated obsessive compulsive disorder: a PET symptom provocation study. Neuropsychopharmacology 2002, 27:782-791.

13. Hoehn-Saric R, Schlaepfer TE, Greenberg BD, McLeod DR, Pearlson GD, Wong SH: Cerebral blood flow in obsessive-compulsive patients with major depression: effect of treatment with sertraline or desipramine on treatment responders and nonresponders. Psychiatry Res 200I, 108:89-100.

14. Swedo SE, Schapiro MB, Grady CL, Cheslow DL, Leonard HL, Kumar A, Friedland R, Rapoport SI, Rapoport JL: Cerebral glucose metabolism in childhood-onset obsessive-compulsive disorder. Arch Gen Psychiatry 1989, 46:518-523.

15. Saxena S, Brody AL, Ho ML, Zohrabi N, Maidment KM, Baxter L.R.,Jr. Differential brain metabolic predictors of response to paroxetine in obsessive-compulsive disorder versus major depression. Am J Psychiatry 2003, 160:522-532.

16. Saxena S, Brody AL, Ho ML, Alborzian S, Maidment KM, Zohrabi N, Ho MK, Huang SC, Wu HM, Baxter L.R.,Jr.: Differential cerebral metabolic changes with paroxetine treatment of obsessivecompulsive disorder vs major depression. Arch Gen Psychiatry 2002, 59:250-261.

17. Van der Linden G., van Heerden B, Warwick J, Wessels C, van Kradenburg J, Zungu-Dirwayi N, Stein DJ: Functional brain imaging and pharmacotherapy in social phobia: single photon emission computed tomography before and after treatment with the selective serotonin reuptake inhibitor citalopram. Prog Neuropsychopharmacol Biol Psychiatry 2000, 24:419-438.

18. Furmark T, Tillfors M, Marteinsdottir I, Fischer H, Pissiota A, Langstrom B, Fredrikson M: Common changes in cerebral blood flow in patients with social phobia treated with citalopram or cognitive-behavioral therapy. Arch Gen Psychiatry 2002, 59:425-433.

19. Seedat S, Warwick J, van Heerden B, Hugo C, Zungu-Dirwayi N, van Kradenburg J, Stein DJ: Single photon emission computed tomography in posttraumatic stress disorder before and after treatment with a selective serotonin reuptake inhibitor. Affect Disord 2004, 80:45-53.

20. MB First, RL Spitzer, M Gibbon, Williams JBW: Structured Clinical Interview for DSM-IV Axis I Disorders - Clinician Edition Biometrics Research Department, New York State Research Institute, NY; 1998.

21. Guy W: ECDU Assessment Manual for Psychopharmacology National Institute of Mental Health, Research Branch; 1976:313-331.

22. Liebowitz MR: Social Phobia. Mod Probl Pharmacopsychiatry 1987, 22: $14 \mid-173$.

23. Goodman WK, Price LH, Rasmussen SA, Mazure C, Fleischmann RL, Hill CL, Heninger GR, Charney DS: The Yale-Brown Obsessive Compulsive Scale. I. Development, use, and reliability. Arch Gen Psychiatry 1989, 46: 1006-10II.

24. Blake DD, Weathers FW, Nagy LM, Kaloupek DG, Gusman FD, Charney DS, Keane TM: The development of a ClinicianAdministered PTSD Scale. J Trauma Stress 1995, 8:75-90.

25. Montgomery SA, Asberg M: A new depression scale designed to be sensitive to change. $B r J$ Psychiatry 1979, 134:382-389.

26. Friston KJ, Frith CD, Liddle PF, Frackowiak RS: Comparing functional (PET) images: the assessment of significant change. $J$ Cereb Blood Flow Metab 199I, I I:690-699.

27. Devinsky O, Morrell MJ, Vogt BA: Contributions of anterior cingulate cortex to behaviour. Brain 1995, I I 8 (Pt I):279-306

28. McDonald AW, Cohen JD, Stenger VA: Dissociating the role of the dorsolateral prefrontal and anterior cingulate cortex in cognitive control. Science 2000, 288: $1835-1838$.

29. Bechara A, Tranel D, Damasio H: Double dissociation of conditioning and declarative knowledge relative to the amygdala and hippocampus in humans. Science 1995, 269: III5-1118.

30. Le Doux J: Fear and the brain: Where have we been, and where are we going? Biol Psychiatry 1998, 44:1229-1238.

31. Rauch SL, Baxter LR: Neuroimaging in obsessive-compulsive disorder and related disorders. In Obsessive-compulsive Disorders:
Practical Management 3rd edition. Edited by: JenikeMA, BaerL and MinichielloWE. St Louis, MI, Mosby; 1998.

32. Hamner MB, Lorberbaum JP, George MS: Potential role of the anterior cingulate cortex in PTSD: Review and hypothesis. Depress Anxiety 1999, 9:1-I4.

33. Rauch SL, Whalen PJ, Shin LM, Mclnerney SC, Macklin ML, Lasko NB, Orr SP, Pitman RK: Exaggerated amygdala response to masked facial stimuli in posttraumatic stress disorder: a functional MRI study. Biol Psychiatry 2000, 47:769-776.

34. Bremner JD: Does stress damage the brain? Biol Psychiatry 1999 45:797-805.

35. Bremner JD, Narayan M, Staib LH, Southwick SM, McGlashan T, Charney DS: Neural correlates of memories of childhood sexual abuse in women with and without posttraumatic stress disorder. Am J Psychiatry 1999, I 56: 1787-1795.

36. Pizzagalli D, Pascual-Marqui RD, Nitschke JB, Oakes TR, Larson CL, Abercrombie HC, Schaefer SM, Koger JV, Benca RM, Davidson RJ: Anterior cingulate activity as a predictor of degree of treatment response in major depression: evidence from brain electrical tomography analysis. Am J Psychiatry 200I, I58:405-4I5.

37. Carey PD, Warwick J, Harvey BH, Stein DJ, Seedat S: Single photon emission computed tomography (SPECT) in obsessvie-compulsive disorder before andafter treatment with inositol. Metabolic Brain Disease 2004, 19:135-144.

38. Saxena S, Brody AL, Schwartz JM, Baxter LR: Neuroimaging and frontal-subcortical circuitry in obsessive-compulsive disorder. BrJ Psychiatry Suppl 1998:26-37.

\section{Pre-publication history}

The pre-publication history for this paper can be accessed here:

http://www.biomedcentral.com/1471-244X/4/30/pre pub
Publish with Bio Med Central and every scientist can read your work free of charge

"BioMed Central will be the most significant development for disseminating the results of biomedical research in our lifetime. "

Sir Paul Nurse, Cancer Research UK

Your research papers will be:

- available free of charge to the entire biomedical community

- peer reviewed and published immediately upon acceptance

- cited in PubMed and archived on PubMed Central

- yours - you keep the copyright
BioMedcentral 